\title{
Do humans dream of android houses? \\ Science fiction architecture as a symbol of rise and fall of Modernism
}

XXIV International Conference

of the Iberoamerican Society

of Digital Graphics

Medellin | Colombia

\author{
Paula Lemos Vilaça Faria \\ PUC MG | Brasil | paulalemosvilaca@gmail.com
}

\begin{abstract}
This research project is about valuing the interdisciplinarity of architecture, using sources from different areas, from fiction and from the imaginary, but which are consistent with the discussions of production and criticism of current architecture. The article is based on the analysis of two short stories, one by the author Ray Bradbury and the other by the author Philip $\mathrm{K}$. Dick as guiding the parallels made with the historiographic theoretical field and the current context, in order to relate the themes and leave gaps for future discussions and possible future alternatives through architecture.
\end{abstract}

Keywords: Architecture; Science Fiction; Technology; Literature.

\section{INTRODUÇÃO}

O presente artigo pretende realizar um paralelo entre o campo especulativo da ficção e a relação com a história da arquitetura, a partir da análise de literatura de ficção científica, tomando como base os livros "Sonhos elétricos", de Philip K. Dick (1954), e "As Crônicas Marcianas", de Ray Bradbury (1958). Foram selecionados um conto de cada livro, "Peça de Exposição" de K. Dick, e "Chuvas leves virão" de Bradbury, de forma que possibilitasse um maior aprofundamento de acordo com as reflexões propostas. Essas reflexões se combinam à leitura de bibliografia teórica de arquitetura, destacando-se Fredric Jameson, teórico de base marxista que faz incursões pela crítica literária, e Jean-Louis Cohen, um crítico do Modernismo, quando essas críticas já estavam estabelecidas, além do autor Marshall Berman, que disserta sobre o declínio da modernidade.

O processo de pesquisa possui como objeto a casa modernista, provida de aparatos tecnológicos advindos do boom da indústria de bens de consumo do período pósguerra, com uma forma arquitetônica um tanto pasteurizada, presente nos subúrbios norte-americanos dos anos 1950 e 1960, como símbolo de uma época na qual são escritas várias histórias de ficção científica, utilizando-se da mesma e transportando-a para o futuro. A escolha desse universo imagético é justificada pela familiaridade prévia com as produções cinematográficas de Hollywood, que ajudaram a delinear essa simbologia baseando-se nos autores selecionados.

O recorte realizado para o processo de pesquisa proporcionou utilizar como metodologia e leitura dos contos combinada à teoria em arquitetura, possibilitando as novas interpretações e indo adiante com o paralelo em relação ao contexto atual. Como produto de uma iniciação científica, as trocas dentro do grupo de pesquisa e com o orientador também foram essenciais para o estabelecimento de diferentes pontos de vista e linhas de raciocínio. Nesse contexto, buscou-se investigar a relação entre a literatura de ficção científica envolvendo tecnologias que hoje já são parte do cotidiano e as possibilidades de ser utilizada como fonte de estudo para a arquitetura, uma vez que são destes materiais que surgem muitas utopias pensadas na prática pelo campo arquitetônico em períodos historicamente complexos.

\section{A CASA COMO SIMULACRO DE UMA ÉPOCA}

Todas as casas de todas as épocas contam uma história de onde e de quando foram projetadas. Victor Hugo (2013), em "O Corcunda de Notre Dame", cita em uma passagem que apesar da invenção da imprensa, que posteriormente iria difundir os livros e outros impressos em larga escala, possibilitando a rápida difusão da história, a arquitetura ainda permaneceria como uma das maiores fontes de estudo e registro sobre as épocas pelas quais determinadas edificações seguiram de pé.

O Movimento Modernista, com seus princípios de progresso e inovação, de minimalismos, funcionalismos, racionalismos, "menos é mais", aliado às correntes positivistas, gerou projetos arquitetônicos de grande valia para o estudo historiográfico do século XX. $\mathrm{O}$ arranha-céu se tornou símbolo das grandes cidades, colocando os Estados Unidos como epicentro do movimento, importando arquitetos de diversos lugares do mundo. Assim, o Modernismo acabou por ganhar toques do american dream e do american way of life, onde os subúrbios e suas "máquinas de morar" com referências à Le Corbusier estão separados dos centros de trabalho das grandes cidades, porém, com os avanços tecnológicos, conectados de forma simples e rápida pelo reluzente automóvel que transformou o cotidiano e a sociedade capitalista.

A fabricação e reprodução em massa de bens de consumo acabou por ser levada pela publicidade à arquitetura, criando um modelo de casa considerado perfeito para a família norte americana de classe média dos anos 1950. Os bangalôs, com jardins na fachada e um acesso à garagem para abrigar o automóvel - quase como um item funcional-decorativo das residências -, cores claras e pasteurizadas, fachadas minimalistas com poucos 
ornamentos, fazendo uso de madeira e vidro. Um dos itens chave da casa modernista da época eram os televisores, de onde vinham os anúncios que levavam os moradores a adquirir a maior parte de seus produtos, principalmente os eletrodomésticos, que se tornavam obsoletos com certa facilidade. A organização espacial em função de uma família nuclear, mas já respeitando certas individualidades e setorizações, com quartos individuais, sendo uma suíte para os pais e outros quartos para os filhos, com um banheiro compartilhado. A sala de estar colocada de forma separada da de jantar, organizando a vida cotidiana por meio dos espaços. Essa é a casa da qual partem os dois contos analisados neste estudo, onde até mesmo os autores moraram em algumas versões, como Philip K. Dick, durante seus casamentos e em seus momentos mais psicodélicos e frutíferos para a sua produção literária (Carrére, 2016).

Um tanto como uma persona nessas histórias, muito pelos filmes da época difundidos no mundo inteiro, o estereótipo dessa edificação foi marcado no imaginário coletivo por Hollywood, e extrapolado para outras realidades em outros tempos, mas partindo muitas vezes desse mesmo ponto e desse mesmo sentimento de esperança de um mundo melhor em meio a uma tensão mundial, quando pairava a ameaça nuclear do período da Guerra Fria.

Porém, cabe aqui a observação de que ao longo do processo de pesquisa foi possível perceber que talvez essa casa estadunidense, de tão enraizada pelo audiovisual no subconsciente ocidental, era quase um símbolo universal da época. É pertinente a reflexão sobre outras casas de outros lugares na década de 1950, na qual o Modernismo percorria anos dourados, mas não estava tão longe assim de sua saturação e declínio. No Brasil, por exemplo, a arquitetura importava elementos modernos e possuía grandes nomes nacionais conhecidos mundialmente, como Oscar Niemeyer, e observava a construção de Brasília como a cidade bossa-nova, mas que, nas palavras de Lorenzo Mammì (2010) "fornece à cultura brasileira um de seus traços fundamentais: a saudade do que ainda não é", deixando uma grande incógnita de qual e como seria essa casa brasileira e em outras culturas diferentes da estadunidense, característica e peculiar em outras histórias imaginadas em outros tempos.

\section{K. DICK E BRADBURY, OS PÓS MODERNOS}

\section{K. DICK E A CASA DATADA}

Philip K. Dick, no conto "Peça de Exposição" (1954), fala de uma casa-relíquia, similar à da narrativa de Bradbury, que será discutida no capítulo posterior. O conto é narrado a partir do personagem George Miller, funcionário da "Agência de História", dentro de uma torre de escritórios do século XXII, no andar "Meados do Século XX". Seu trabalho consiste em recriar fisicamente elementos deste século, sendo sua obra prima uma casa extremamente parecida, segundo a descrição do livro, a uma casa construída nos anos 1950/1960.

"Era uma casa bela e pequena; se ele tivesse vivido naquela época, gostaria de ter tido uma igual. Três quartos, um bangalô californiano de estilo rústico. Lareira num canto. Tapetes bordô. Um sofá moderno e uma cadeira confortável. Uma mesa de centro em madeira de lei e tampo de vidro. Cinzeiros de cobre. Um isqueiro e uma pilha de revistas. Elegantes luminárias de chão em plástico e aço. Uma estante de livros. Um televisor. Uma janela ampla com vista para o jardim da frente. Ele atravessa a sala para chegar ao corredor. A casa era incrivelmente completa. (Dick, 1954. P. 12-13)

Miller é um nostálgico anacronista, visto por seus colegas de trabalho como alguém apaixonado por "malditas réplicas autênticas de ninharias descartadas", que idolatra o passado quando "ele está morto e enterrado", sendo o seu presente em uma época - no conto o século XXII - na qual a sociedade progrediu, enquanto seus objetos de estudo são meras "réplicas imperfeitas". A história tem seu ponto de virada quando Miller, em um dia de trabalho e verificação das peças, entra na casa e é transportado para o século $X X$, e está a caminho de buscar o jornal na porta da casa, que é sua, onde mora com sua família. Ele é um homem de negócios da gestão americana de Eisenhower, com dois filhos e uma bela esposa. Mas a personagem não se sente pertencente à essa época, e não consegue se lembrar qual é sua realidade definitiva, seu presente. Assim, a personagem resolve ir a um psiquiatra na realidade de "conforto e liberdade" do pós-guerra dos anos 1950, levando esse sentimento de insubstancialidade das duas realidades paralelas das quais se sente parte, para tentar chegar à conclusão de qual era a verdadeira. Ele passa a refletir se ele mesmo não é uma peça de exposição, "uma réplica artificial do passado", ao que diz o psiquiatra:

\footnotetext{
“- Você sabe, claro, que essa é uma sensação comum para a maioria da humanidade. Especialmente durante períodos de grande tensão. Aliás, onde estava o jornal? Você o encontrou? [...] Essa é uma fonte de irritação para você? Vejo que você reage com firmeza a qualquer menção ao jornal." (Dick, 1954. P. 20)
}

Ao mesmo tempo, quando Miller descreve o "futuro", o psiquiatra encara este tempo como uma alucinação reconfortante, uma fantasia de escape, com robôs e tecnologias, sem frustrações. Ou seja, há insatisfação nas duas realidades possíveis e Miller é visto como alguém em meio a um surto psicótico em ambas. O personagem no conto opta por permanecer no século XX - o autor não deixa claro como ele navega entre as épocas, mas existe esse fácil intercâmbio temporal -, mas ao encontrar o jornal se depara com notícias sobre a ameaça de um míssil vindo da Rússia. Há uma fatalidade em ambas, um futuro opressivo onde não há possibilidade de nostalgia pelo passado, e um passado entrando na iminência da guerra fria, com a ameaça nuclear, que encerra o conto.

Imageticamente, pode-se fazer o paralelo com a casa de Truman, no filme "The Truman Show" (1998). Truman vive em um subúrbio cenográfico norte americano, e, assim como Miller, assume o estereótipo do "homem de negócios" em Seaside, na Flórida. Porém, sua vida é, sem seu conhecimento, um reality show gravado desde o seu nascimento e transmitido ao vivo no país. O filme tem essa particular semelhança do estranhamento de Truman com a sua realidade, assim como Miller, mas que é até certo ponto anestesiado pelo conforto do cotidiano, dado principalmente pela casa cheia de comodidades. Pode-se concluir então, que de certa forma, a casa moderna é um tipo de espaço alienante, que traz a sensação de "estar tudo bem" mesmo quando não está, principalmente pelo fato de o desconforto estar "do lado de fora". 


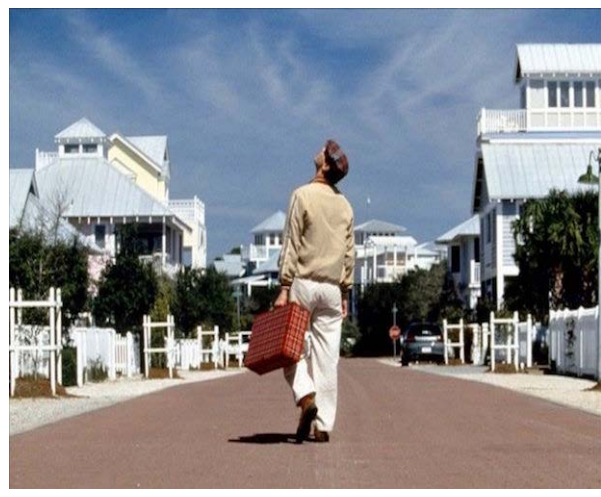

Figura 1: O subúrbio norte-americano padronizado de The Truman Show

Tanto o filme quanto o conto dizem sobre uma lógica espacial bastante comum nos Estados Unidos, os subúrbios, que fazem uma clara separação entre os chamados "setores da vida urbana" segundo Le Corbusier, colocando a casa nesse lugar de complacência onde nada mais importava uma vez que se estava em seu lar, com sua família e suas regalias tecnológicas.

É possível fazer um paralelo claro com o aumento, em pleno século $\mathrm{XXI}$, do número de condomínios fechados ao redor do mundo, que vendem a sensação de "segurança e tranquilidade", longe dos tumultuados centros urbanos. O simulacro do isolamento tem se tornado mais presente, e mais eficaz, principalmente ao segregar classes sociais distintas, com base em um medo da violência, e pelo individualismo exacerbado da contemporaneidade. E como uma continuidade dessas narrativas, todos esses itens são produtos à venda no mercado. O capitalismo lucra em cima da ideia dessa casa, tanto no design mais atrativo quanto nos itens pertinentes a esse morar, mas agora com a possibilidade de se isolar fisicamente dentro de fronteiras, mas se manter conectado pelas redes de informação, colocando a casa de K. Dick não mais como uma peça de exposição antiquada e obsoleta, mas repaginada, mais polida e conectada ao público que não está em meio a uma guerra fria, e sim a uma guerra dos lugares (Rolnik, 2019).

Além disso, hoje a ameaça nuclear de uma guerra fria é um medo um tanto obsoleto e datado, e o mundo enfrenta sistemas mais perenes, que mesmo na contemporaneidade, seguem encarados por boa parte da população - a parcela que muito provavelmente moraria em casas modernas de classe média dos anos 1950 como a do conto analisado - de forma blasé, levando a reflexões como a de Fredric Jameson, que sugere que hoje não se sabe exatamente se o colapso se daria "numa explosão ou num murmúrio", mas provavelmente em um derretimento lento, assim como escrito por Ursula K. Le Guin em seu livro "A curva do sonho", e de acordo com o capitalismo enraizado no modus operandi do século XXI.

"Pois é o fim do mundo que está em questão aqui; e seria divertido se o apocalipse fosse a única maneira de imaginar o desaparecimento desse mundo (e se seria numa explosão ou num murmúrio, não é essa a questão que importa). É o velho mundo que merece o fel e a sátira; este novo é apenas o apagamento de si mesmo, o deslizamento para o que Philip Dick chamava de kipple ou gubble, para o que [Ursula K.] descreveu uma vez [em The Lathe of Heaven] como edifícios "se desmanchando. Estavam ficando moles e empapados, como gelatina ao sol. Os cantos já tinham escorrido pelas laterais, deixando enormes manchas cremosas". Certa vez alguém disse que é mais fácil imaginar o fim do mundo do que o fim do capitalismo. Agora podemos rever essa ideia e testemunhar o esforço de imaginar o capitalismo, imaginando o fim do mundo." (Jameson, 2013. P. 201)

\section{BRADBURY E A SUA CASA INTELIGENTE}

A casa, em uma quantidade razoável dos contos do escritor norte americano Ray Bradbury, mais especificamente a partir dos contos do livro "As crônicas marcianas", é a casa dos sonhos do boom da indústria de bens duráveis e de consumo dos Estados Unidos, transportada de uma época pré-corrida espacial a um futuro no século seguinte. O fetichismo pela enorme quantidade de eletrodomésticos incorporados à rotina de seus moradores é parte deste cenário em que esses mesmos itens eram símbolos de um certo auge tecnológico, ainda em constante desenvolvimento.

A análise da casa de Ray Bradbury se dá a partir do conto "Chuvas leves virão" (1958), que integra o livro "Crônicas Marcianas". Nesse fragmento temporal que a narrativa se coloca, é possível ver o fetichismo de mercadoria exacerbado na tecnologia que o opera, e a sua melancolia ao não ser mais subserviente aos seus moradores.

"A casa se erguia solitária em uma cidade de destroços e cinzas. Era a única intacta. À noite, a cidade em ruínas irradiava um brilho radioativo que podia ser visto de quilômetros de distância." (Bradbury, 1958. P. 269)

A história se passa no ano de 2026, e a personagem principal é a casa, a última ainda de pé após uma explosão radioativa. O relógio acorda o espaço, em tese, seus moradores, narrando em que dia está e que horas são, quais os eventos importantes do dia e anunciando alguns produtos relacionados, no caso capas de chuva, pois a previsão do tempo diz que talvez chova. A similaridade com as notificações que chegam toda manhã nos smartphones é nítida, e é possível ter essa narração de informações atualmente pelos dispositivos smart speakers, como o Echo Dot, da Amazon (com a smart assistant Alexa), o Homepod, da Apple (com a smart assistant Siri) e o Nest, da Google (com a smart assistant Google Assistant). A Alexa por exemplo, chegou ao Brasi em 2019, ou seja, são dispositivos bem recentes vindo de um imaginário antigo que já virou até desenho animado (Os Jetsons, 1962) antes de ser algo concreto. Trata-se do desenvolvimento do conceito de IOT, "Internet of Things", que se refere à conexão dos objetos cotidianos à internet, a partir de sensores inteligentes e softwares que transmitem dados à rede. Não só as pessoas se colocam dentro da rede informacional, mas várias ferramentas físicas se adaptam à isso, como um smart watch que possibilita o controle de quando mudar uma música em um dispositivo de som conectado dentro de determinado ambiente.

A casa de Bradbury vai além de um relógio inteligente. Toda a edificação opera de forma automatizada, incluindo todos os eletrodomésticos, que fazem todas as refeições de forma automática e contínua, e um tanto devota, como "serviçais" em um "altar", mesmo sem os seus "deuses" a serem servidos, como é descrito no conto. Há uma extrapolação da casa completa em itens da moda e tecnologia da época, não se tratando apenas de um 
simples liquidificador ou uma batedeira de última geração, mas sim, itens que se operam de forma autônoma, independente do usuário, para dinamizar o cotidiano e deixar as suas tarefas habituais mais práticas.

Essa automatização dos processos a partir dos eletrodomésticos e da própria estrutura da casa criada no conto coloca em questão a existência de alguém a quem a casa está servindo. As sombras dos antigos moradores carbonizados enquanto robôs leem fielmente poemas e histórias todas as noites e fazem soar relógios em horários rigorosamente colocados para refeições e atividades que percorrem o cotidiano daquela família, como "aprontar as crianças para o colégio", evidenciam até mesmo como a arquitetura está correlata aos hábitos, e se adapta ao cotidiano de seus ocupantes.

"A casa matutina estava vazia. O relógio continuava a marcar as horas, repetindo sua ladainha no vazio: Sete e nove, hora do café da manhã, sete e nove!" (Bradbury, 1958. P. 268)

A partir do momento em que um acidente provoca a faísca de um incêndio, a casa tenta lidar com o fato de forma corriqueira, trazendo os caricatos "ratinhos ajudantes" para apagar o fogo. A cozinha enlouquecida em meio ao fogo segue produzindo ovos e bacon para ninguém, trazendo a ideia de que a tecnologia é útil principalmente quando alguém a utiliza, mas em contraponto com o presente, é muito claro como as pessoas também são úteis à tecnologia. Todos os dados disponibilizados hoje voltam em otimizações em qualquer item tecnológico, mas no conto, não houveram adaptações ou atualizações, apenas uma espécie de movimento perpétuo que apesar de manter a casa em funcionamento, foi também parte da causa de seu desgaste.

"Na cozinha, um instante antes da chuva de fogo e de madeira, era possível ver o fogão preparando cafés da manhã em ritmo psicopata, dez dúzias de ovos, seis pães inteiros de torradas, vinte dúzias de tiras de bacon que, engolidas pelo fogo, fizeram com que o fogão começasse a trabalhar de novo, chiando histericamente!" (Bradbury, 1958. P. 276)

Porém, à medida que o colapso da casa se torna iminente, todos os esforços são em vão, não há água suficiente nos reservatórios para um efetivo combate ao incêndio, e mais uma vez é feita uma analogia à chuva, que nesse caso é complacente e anestesiada, sem forças para resolver todo o caos da situação. Analogia cabível também à época, relacionada às ideias de Marshall Berman (1986) em sua obra "Tudo que é sólido desmancha no ar", na qual se discorre sobre a velocidade do tempo na modernidade, que acelera o ritmo das transformações e o estreitamento da comunicação e locomoção, mas gera uma enorme instabilidade que segue acompanhando a angústia melancólica diante da passagem desse tempo veloz. Assim, a casa atinge sua destruição completa em um tom fatalista de movimento contínuo a caminho do próprio fim, pontuando a tecnologia como algo que pode resistir tempos pós-humanos, mas não necessariamente de forma eterna.

"O amanhecer apareceu fraco do lado leste. Entre as ruínas, uma parede se erguia solitária. Dentro da parede, uma última voz repetia, sem parar, mesmo depois que o Sol se ergueu e brilhou sobre a pilha de escombros e fumaça. Hoje é 5 de agosto de 2026, hoje é 5 de agosto de 2026, hoje é..." (Bradbury, 1958. P. 276)
Pode-se perceber de forma clara a relação do conto de Bradbury com a animação "Os Jetsons". As obras são contemporâneas, e apresentam anseios da época, na qual via-se a mudança de paradigmas de consumo iminente, bem como o aumento da rapidez na qual os itens eram produzidos. Além disso, a ameaça nuclear, trabalhada de forma mais explícita no conto de K. Dick discutido anteriormente, gerou fantasias de um conforto que apenas a tecnologia traria às pessoas, desde a dinamização das tarefas cotidianas até a forma com que se davam as relações interpessoais e com o espaço. A faísca do individualismo é clara no conto, uma vez que a casa é uma sobrevivente que funciona com um fim em si mesma, sem uma conexão com a vizinhança, já dizimada, servindo apenas a seus moradores e a si mesma. Dessa forma, existe uma intercessão entre os dois contos, que aponta para o presente.

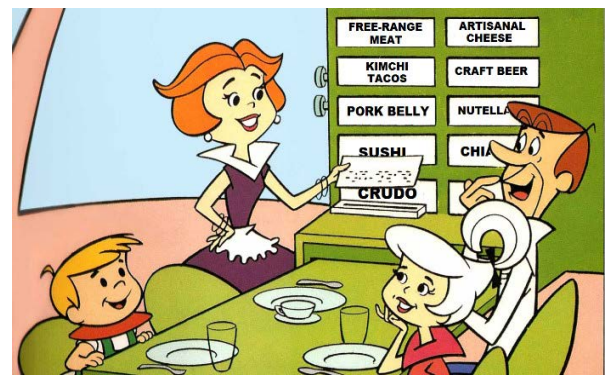

Figura 2: Os Jetsons e sua casa automatizada

Além da suburbanização da vida cotidiana demonstrada pelo conto de K. Dick, o conto de Bradbury se coloca como um certo espelho do desejo do presente, que pode gerar também um alerta às consequências dessas vontades de se morar em uma edificação que acaba por ser o simulacro do isolamento e de se possuir toda e tanta tecnologia em seu interior. Tanto pelos contos quanto pelo presente, percebem-se as possibilidades de alienação por meio dessas invenções e da repetição do cotidiano, tirando a atenção do mundo externo, onde a tecnologia não necessariamente está integrada exatamente de forma benéfica e como símbolo de progresso, e, principalmente, não é acessível a todos.

Com isso, há uma possível pontuação de uma vanguarda que veio pelo meio ficcional, a partir tanto do conto de Bradbury quanto o de K. Dick, explicitada em um breve panorama da época de 10 a 20 anos após a publicação dos contos (1970), dado por Guilherme Wisnik, em sua obra "Espaço em obra - Cidade, arte, arquitetura":

"Nas duas últimas décadas, o rápido desenvolvimento das tecnologias da informação foi acompanhado pelo grande aumento da mobilidade e da liquidez do capital, em processos econômicos realizados de forma cada vez mais transnacional, envolvendo permanentes fluxos de mão de obra, matérias-primas, pessoas e mercadorias. $\mathrm{Na}$ verdade, desde pelo menos o início dos anos 1970, uma fundamental mudança de paradigma alterou a base produtiva do mundo, e com ela a representação simbólica da sociedade capitalista. Refiro-me à virada histórica ocorrida em torno de 19711973, em que se deu a mudança de um paradigma fordista de produção para um sistema de acumulação flexível, voltada para produtos específicos e nichos de mercado, chamado também de capitalismo tardio. Processo que, no campo da cultura, corresponde à 
passagem do modernismo ao pós-modernismo." (Wisnik, 2018. P. 204)

O pós-modernismo veio com a saturação do modernismo. A pasteurização da reprodução em massa deu lugar ao fluxo ainda mais veloz de informações, e a tecnologia passou a ocupar um lugar de destaque maior, e de acumulação nesse novo fluxo de mercado. A casa moderna de K. Dick e Bradbury já caía num certo kitsch, um melodrama ficcional de um contexto ultrapassado, sentimento de certa forma antecipado pelos dois autores, que por meio da ficção científica futurista imaginaram um futuro no qual essas casas contavam outras histórias sobre o seu presente, sobre anseios e questões que ainda estavam ensaiando entrar em curso. Com isso, a análise da imaginação dessas obras permite uma interpretação relevante para a arquitetura, em um momento no qual não há coletivos como o Archigram ou o Ant Farm, e se carece de utopias. Busca-se com essa discussão semear e reforçar uma valorização da interdisciplinaridade da arquitetura, utilizando fontes de áreas diferentes, da ficção e do imaginário, mas que se fazem coerentes com as discussões de produção e crítica da arquitetura em curso atualmente.

\section{CONCLUSÃO}

"A casa tremia a cada ruído. Se um pardal encostava em uma janela, a persiana se erguia de supetão. O passarinho, assustado, fugia voando! Não, nem um passarinho tinha direito de encostar na casa!" (Bradbury, 1958. P. 270)

Já foi dito que a tecnologia e seus avanços libertariam as pessoas (Gandini, 2003) para que não precisassem trabalhar tanto. Hoje, a casa já não possui mais seu caráter de isolamento concreto do cotidiano, uma vez que a tecnologia borrou as fronteiras de dentro e fora, deixando a linha entre trabalho em um espaço e descanso em outro também extremamente tênue, trazendo ao mesmo tempo a liberdade de conhecer um mundo dentro da própria casa por meio das redes, mas não exatamente uma liberdade concreta, uma vez que atualmente os dados são a moeda de troca mais valiosa do mundo, operando no câmbio tecnológico, não só nas casas, mas em todos os lugares.

O momento presente em que a humanidade se encontra coloca a casa em uma posição essencial, levantando inúmeras discussões, principalmente sociais sobre o direito à moradia e a desigualdade da qualidade dos espaços das residências. Quando se fala em isolamento, pensa-se imediatamente no conforto do lar, de se possuir um abrigo para cuidar de si e dos seus, dada a atual pandemia do COVID-19. Uma crise global, que já arrasta uma série de consequências e debates em todos os âmbitos, principalmente da automação. Quando grande parte da população se coloca em quarentena, os robôs, personagens comuns às narrativas de ficção científica, se tornam parte da discussão do futuro próximo e até mesmo do presente. Ironicamente, em 2021 a palavra "robô", escrita pela primeira vez em uma peça de 1921 do escritor checo Karel Čapek completa seu centenário. Palavra que no contexto da peça significava "escravo".

Há grande pertinência ao se imaginar a casa em realidades paralelas ou futuras, uma vez que se vive um contexto que poderia facilmente ter sido escrito em algum livro de ficção científica de alguns anos atrás. Uma pertinência também em avaliar se as "casas inteligentes" de hoje são eficientes o bastante como lugar de proteção de seus moradores, se realmente são contrários do conto de Ray Bradbury discutido. Como todo esse aparato contribui para o morar? Qual o impacto do isolamento em um lugar de hiper conectividade, onde mesmo sem poder sair de casa há um bombardeio de notícias chegando pelos dispositivos inteligentes, tirando boa parte do aspecto de refúgio do lar? A explosão radioativa de "Chuvas leves virão" pode ser substituída pelo esgotamento mental proporcionado pelo isolamento? Barra-se o vírus - que ocupa o lugar da explosão - mas não é barrada a grande quantidade de reportagens sobre decoração e produtividade e promoções em lojas de mobiliário e itens para casa durante o período de quarentena. Os anúncios, como os de capas de chuva do conto não são tão aleatórios assim. Está se formando uma espécie de obsessão pela casa? Quem sabe este não seja o cliff hanger para um próximo conto de ficção.

E ainda, em todo esse contexto dado, tem-se também o desafio colocado para a própria arquitetura. Se a casa é o ponto central em um período de quarentena, como deve ser essa casa? Ela é acessível e adaptável em sua forma para momentos de crise? Já se sabe a resposta da última pergunta. Hoje, apenas na cidade de São Paulo, uma das cidades mais populosas do país, há 24.344 pessoas em situação de rua segundo o Censo de 2019 (G1 SP e TV Globo, 2020). Nas favelas, $56 \%$ dos moradores conseguem se manter em isolamento e com suprimentos por apenas uma semana (Galvani, 2020). Tanto o isolamento quanto a casa atualmente não são para todos.

Esse artigo se propôs a discutir a casa em outras realidades, mas enfrenta-se hoje além de um período historicamente crítico de distanciamento social, o gigantesco distanciamento econômico entre a população do país. A casa tecnológica, como representação do brilhantismo humano, capaz de proporcionar um isolamento com um mínimo de conforto, é a realidade de uma parcela bastante pequena da população, enquanto para outras, segue sendo apenas um personagem de uma ficção em um futuro distante.

Por isso, devem ser colocadas afinal, algumas perguntas: para quem e como serão as casas tecnológicas e eficientes do futuro? Como a arquitetura pode ser parte ativa concreta em situações emergenciais, propor alternativas, levando a um patamar relevante de discussão sobre o morar em tempos de isolamento? Quais as utopias que permitem imaginar hoje o futuro que se supõe construir? Voltemos então a ler e a escrever ficções, lugares nos quais tudo ainda é possível.

\section{RESULTADOS}

Como resultado desta pesquisa, foi possível perceber a partir dos contos de ficção selecionados a capacidade de ser pontuada uma espécie de antecipação da melancolia e saturação em relação ao Modernismo. Ambas as histórias se colocam em uma grande distância temporal do momento em que foram escritas, mas demonstram um certo esfacelamento do presente dos autores, uma vez que as tecnologias não são capazes de suprir ou mudar alguns pontos da humanidade, seja em uma casa equipada tecnologicamente ou em um eterno apreço pelo novo e certo hábito humano de subjugar o passado. 


\section{AGRADECIMENTOS}

Agradeço primeiramente ao meu orientador, Paulo Waisberg, que aceitou embarcar nessa viagem para outras realidades e futuros possíveis, que acabou culminando em um presente igualmente preocupante, mudando boa parte do tom das ficções lidas para o desenvolvimento do trabalho. Agradeço à professora Gabriela Pires Machado, que desde a escrita da proposta do projeto me encorajou a não desistir de escrever, e em todo o processo foi revisora de textos e fornecedora de bibliografias. Um agradecimento especial ao grupo de pesquisa "Design e Fabricação Digital", dentro do qual me encaixei e tive várias discussões com outros professores sobre a pesquisa, seu futuro e relevância, especialmente o professor Sérgio Saraiva. E por fim, agradeço Rafael Marcial, pelo empréstimo de grande parte dos livros lidos de antemão antes da seleção de apenas dois como principais a serem discutidos, e também pelo estímulo de seguir com um projeto de pesquisa em tempos turbulentos e sem nenhum incentivo, dados os lamentáveis cortes no setor de pesquisa do estado e do país.

\section{REFERÊNCIAS}

\section{REFERÊNCIAS LITERÁRIAS}

Berman, M. (1986). Tudo que é sólido desmancha no ar - A aventura da modernidade. Título original: All that is solid melts into air. Tradução: Carlos Felipe Moisés, Ana Maria L. Ioriatti e Marcelo Macca. São Paulo: Companhia Das Letras.

Bradbury, R. (2013). As crônicas marcianas. Título original: The Martian Chronicles. Tradução: Ana Ban. Apresentação Jorge Luis Borges. - 2. ed. São Paulo: Globo.

Čapek, K. (2001). R.U.R. Robôs Universais de Rossum. Título original: Rossumovi Univerzální Roboti. [S.I.]: Dover Publications.

Carrère, E. (2016). Eu estou vivo e vocês estão mortos. Título original: Je Suis Vivant Et Vous Etes Mort. Tradução: Daniel Lümann. São Paulo: Aleph.

Cohen, J. (2013). O futuro da arquitetura desde 1889: Uma história mundial. Título original: The future of Architecture since 1889. Tradução: Donaldson M. Garschagen. Revisão técnica: Sylvia Ficher. São Paulo: Cosac Naify.

Dick, P. (2018). Sonhos Elétricos. Título Original: Electric Dreams. Tradução Daniel Lümann. São Paulo: Aleph.

Dick, P. (2014). Androides sonham com ovelhas elétricas? Título original: Do androids dream of electric sheep? Tradução Ronaldo Bressane. São Paulo: Aleph.
Galvani, G. (2020). Nas favelas, 56\% conseguem se manter apenas por mais uma semana, diz pesquisa. Disponível em: https://www.cartacapital.com.br/saude/nas-favelas-56conseguem-se-manter-apenas-por-mais-uma-semana-dizpesquisal

G1 SP e TV Globo. (2020) População de rua na cidade de SP aumenta $53 \%$ em 4 anos e chega a 24 mil pessoas. Disponivel em: https://g1.globo.com/sp/saopaulo/noticia/2020/01/30/populacao-de-rua-na-cidade-de-spchega-a-mais-de-24-mil-pessoas-maior-numero-desde2009.ghtml

Hugo, V. (2013). O corcunda de Notre Dame: edição comentada e ilustrada. Título original: Notre Dame de Paris. Tradução, apresentação e notas: Jorge Bastos. - 1.ed. Rio de Janeiro: Zahar.

Jameson, F. (2013). In: SYKES, Krista (org.). O campo ampliado da arquitetura: Antologia teórica 1993-2009. Título original: Constructing a New Agenda: Architectural Theory 1993-2009. Tradução: Denise Bottmann, com a colaboração de Roberto Grey. Revisão técnica: Ana Luiza Nobre. São Paulo: Cosac Naify.

Le Guin, U. (2019). A curva do sonho. Título original: The Lathe of Heaven. Tradução: Heci Regina Candiani. São Paulo: Editora Morro Branco.

Mammì, L. (2010). In: Heloísa Espada (org.). As construções de Brasilia. São Paulo: Instituto Moreira Salles.

Tadeu, T. (2009). Antropologia do ciborgue: as vertigens do póshumano. Organização e tradução Tomaz Tadeu - 2. ed. Belo Horizonte: Autêntica Editora.

Wisnik, G.; Mariutti, J. (2018). Espaço em obra: cidade, arte, arquitetura. São Paulo: Edições Sesc São Paulo.

\section{REFERÊNCIAS CINEMATOGRÁFICAS}

The Truman Show (O Show de Truman - O Show da Vida). Direção: Peter Weir. Produção: Scott Rudin, Andrew Niccol, Edward S. Feldman e Adam Schroeder. Estados Unidos: Paramount Pictures, 1998. 1 DVD (102 min.)

The Jetsons (Os Jetsons). Criação: William Hanna e Joseph Barbera. Estados Unidos: ABC Network. Distribuição no Brasil: SBT. Série original: 1962-1963 / Nova série: 19851987. Nº demporadas: 3 . Nº de episódios: 75.

Surplus: Terrorized Into Being Consumers (Excedentes: aterrorizados para ser consumidores, em livre tradução). Direção: Erik Gandini. Cinematografia: Carl Nilsson e Lukas Eisenhauer. Suécia, 2003. Disponível em https://www.youtube.com/watch?v=bXmuWeclQos 